\title{
Assessment of Knowledge and Practices about Denture Hygiene among Complete Denture Wearers in Lahore City
}

\author{
Muhammad Asif Mushtaq ${ }^{1}$ \\ BDS \\ Junaid Altaf ${ }^{2}$ \\ BDS \\ Muhammad Ali Sheikh ${ }^{3}$ \\ BDS \\ Muhammad Waseem Ullah Khan ${ }^{4}$ \\ BDS, FCPS \\ Asif Ali Shah ${ }^{5}$ \\ BDS, MSc, MDS
}

OBJECTIVE: The aim of this study was to determine the level of awareness about knowledge and practices of complete denture hygiene in a tertiary care dental hospital of Lahore.

METHODOLGY: A descriptive, cross-sectional study was conducted in the Department of Prosthodontics, Punjab Dental Hospital/de'Montmorency College of Dentistry, Lahore. A total of 150 patients were included in the study. All patients were selected randomly who were seeking treatment from this tertiary care dental hospital. The questionnaire included data about gender, age, duration of prosthesis use, cleaning methods and materials etc. The collected data was analyzed using SPSS version 20.0. Chi-square test of significance was applied for statistical analysis with a significance level of 5\% ( $\mathrm{p}=0.05)$. RESULTS: The results showed that $49(32.7 \%)$ subjects were wearing the same prosthesis for more than 5 years. Data analysis showed that 44 out of 150 subjects (29.3\%) normally slept with their prosthesis in mouth. 86 patients (57.3\%) told that they were given only verbal instructions about methods of cleaning while $64(42.7 \%)$ were not even told or shown any method of cleaning of denture by dentist. It was observed that 63 individuals (42\%) believe that denture can last from 5-10 years. CONCLUSIONS: Within the limitations of this study, it was concluded that complete denture wearers had limited awareness of denture hygiene and oral care despite using dentures for long time.

KEY WORDS: Complete denture, Oral hygiene, Denture cleansing, Dental care.

HOW TO CITE: Mushtaq MA, Altaf J, Sheikh MA, Khan MWU, Shah AA. Assessment of knowledge and practices about denture hygiene among complete denture wearers in lahore city. J Pak Dent Assoc 2019;28(4):187-191.

DOI: https://doi.org/10.25301/JPDA.284.187

Received: 20 February 2019, Accepted: 09 August 2019

\section{INTRODUCTION}

$\mathrm{A}$ ccording to latest demographic data, life expectancy has increased in both developing and developed countries. The proportion of older people has increased in correspondence to the total population. Approximately 600 million people are of 60 or above worldwide and this number is expected to be doubled by 2025. The process of ageing is relentless leading to inconsistent homeostasis, raised susceptibility to chronic

1. FCPS Resident, Department of Prosthodontics, de'Montmorency College of Dentistry Punjab Dental Hospital, Lahore.

2. FCPS Resident, Department of Prosthodontics, de'Montmorency College of Dentistry Punjab Dental Hospital, Lahore.

3. FCPS Resident, Department of Prosthodontics, de'Montmorency College of Dentistry Punjab Dental Hospital, Lahore.

4. Assistant Professor, Department of Prosthodontics, de'Montmorency College of Dentistry Punjab Dental Hospital, Lahore.

5. Professor, Department of Prosthodontics, de'Montmorency College of Dentistry Punjab Dental Hospital, Lahore.

Corresponding author: "Dr. Muhammad Asif Mushtaq" < dr.asif100@yahoo.com > diseases alongwith decreased reconciliation to external environmental stimuli which affects bodily organs and systems. All these aspects are consociated with more predisposition to systemic diseases and death. ${ }^{1,2}$ Several current studies indicate that association is existing between oral diseases and systemic chronic diseases. ${ }^{3}$

Agonies of old age can be reduced by treating oral diseases alongwith systemic chronic diseases. Despite many advancements in preventive and conservative dentistry, various oral diseases like dental caries, tooth wear lesions, periodontal diseases, trauma and tumors of the jaw lead to loss of many teeth and ultimately edentulism. ${ }^{2}$ The most common treatment worldwide for edentulism is removable complete denture. ${ }^{2,4}$ Maintenance of optimum oral health in denture wearers becomes more difficult which can lead to malodor, poor esthetics, accumulation of plaque/calculus on denture, soft tissue pathologies and even complete failure of the prosthesis. In complete denture wearers, poor oral health can be attributed to inadequate oral hygiene, poor 
manual dexterity, surface roughness of the prosthesis, lack of proper instructions and guidance by the dentist and failure to follow the instructions given by dentist. ${ }^{4,5}$

The main objective of complete denture prosthetic treatment is to improve patient's health by restoring function. The success of this treatment depends on patients' motivation towards correct method of use, maintenance of good oral hygiene and proper guidance by the dentist. Current literature has revealed that patients are not given proper instructions for denture cleansing, general oral health care and need for follow up dental visits. ${ }^{2,6}$ According to American College of Prosthodontists recommendations for care and maintenance of denture, daily careful removal of biofilm present in the oral cavity and on denture surface is of utmost importance for good oral and general health. ${ }^{7}$ Home care instructions are given to the patient to remove this biofilm. Generally, two major methods are recommended for biofilm removal from denture surface. These methods include mechanical cleaning, chemical cleaning or combination of both. Although literature has shown the most effective and common method is mechanical cleaning but chemical cleansers are also used with mechanical methods. ${ }^{8,9,10}$ According to Azad et al, 65\% complete denture wearers clean their denture once only and major method of cleaning was water. ${ }^{11}$ Barbosa et al have mentioned that only $16.8 \%$ complete denture wearers were using chemical denture disinfectants. ${ }^{6}$ Shankar et al have reported that $10.2 \%$ complete denture wearers not given any denture hygiene instructions. ${ }^{2}$ As shown by these studies, there is immense need of improving denture hygiene knowledge and practices in every part of the world.

The objective of this questionnaire based study was to assess the knowledge of complete denture wearers about denture hygiene visiting a tertiary care hospital in Lahore city. This knowledge and practice assessment was used to determine the level of awareness about denture care and maintenance .According to previous studies, there was need to increase the standard of denture hygiene habits in complete denture wearers. So, there is continuous need of reassessment of knowledge about denture hygiene habits. This evaluation will help clinicians to emphasize more on denture hygiene by better patient education.

\section{METHODOLOGY}

This cross sectional descriptive study was conducted in the Department of Prosthodontics, Punjab Dental Hospital/de'Montmorency College of Dentistry, Lahore from May, 2018 to December, 2018. Permission from the hospital ethical committee was taken. Informed consent Performa was filled for every patient. It was made sure that every patient understands the purpose of study and its clinical implications. They were assured about the confidentiality of their collected data. A total of 150 patients were interviewed and included in study. All patients were selected randomly who were seeking treatment from this tertiary care dental hospital. The validated questionnaire was prepared from previous studies. ${ }^{6,12}$

The collected data was analyzed using SPSS version 20.0. Percentages and frequencies were calculated for categorical variables like methods of denture cleansing, gender, age of denture. Mean and standard deviation was calculated for numerical variables like age. Chi-square test of significance was applied for statistical analysis keeping $\mathrm{p} \leq 0.05$ as significant.

\section{RESULTS}

A total of 150 patients were selected, 102 of whom (68\%) were male and $48(32 \%)$ were female. The age range was 21-95 years with a mean age of 63.39 years with $59.3 \%$ between 50-70 years of age (Fig.1). Patients were categorized according to the duration of usage of prosthesis in three

Fig 1: Age Distribution of Participants

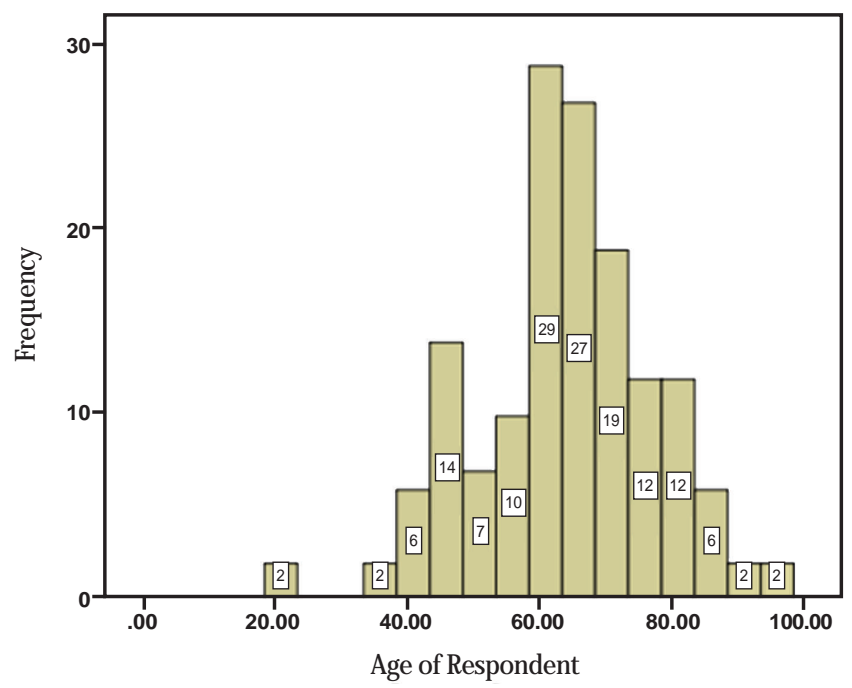

groups with at least 6 months of usage. 6 months to one year group was of $n=50(33.3 \%), 1-5$ year group was $n=51$ $(34 \%)$, more than five years use was $\mathrm{n}=49(32.7 \%)$. Data analysis showed that 44 out of 150 subjects (29.3\%) normally slept with their prosthesis in mouth (Fig.2) out of these 44,35 were male and 9 were female and a chi square was performed with weak relationship between gender and sleeping with prosthesis $(\mathrm{x} 2=3.81, \mathrm{p}=0.051)$ (Table.1). Major method of

When questioned about frequency of cleaning their complete denture daily, 66 subjects (44\%) reported cleaning their prosthesis once a day while only 42 individuals (28\%) 
reported cleaning their prosthesis three or more times a day and strong relationship was found between gender and frequency of cleaning the prosthesis $\left(\mathrm{x}^{2}=14.58, \mathrm{p}=0.002\right)$

Fig 2: Percentage of participants sleeping with prosthesis in month

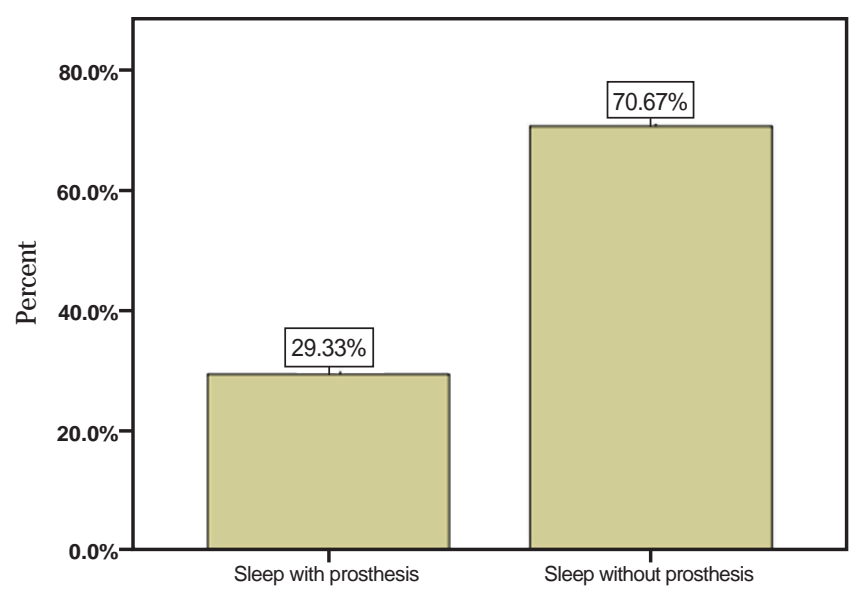

Sleeping with Complete denture in mouth

Fig 3: Frequency of cleaning of prosthesis

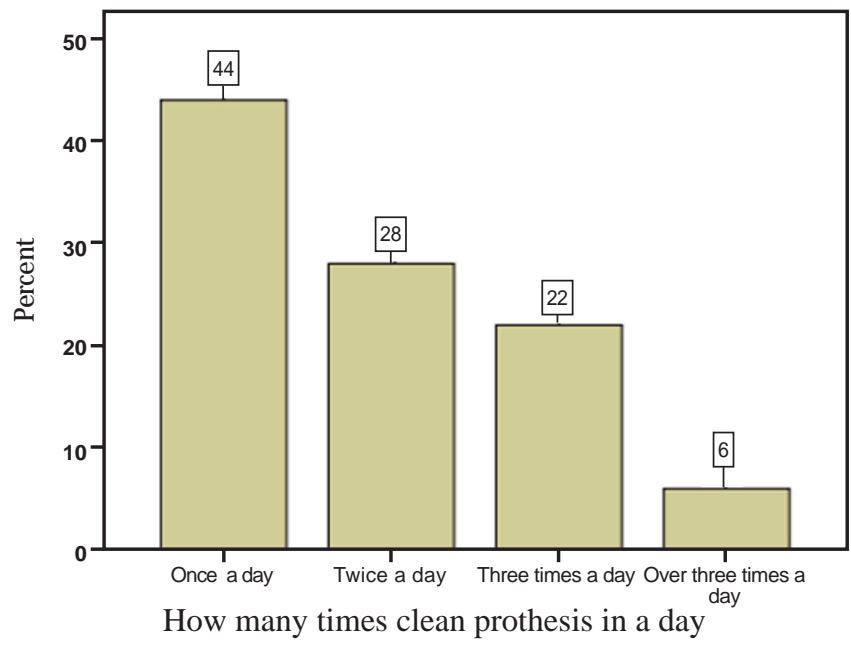

Table 1: Denture hygiene knowledge and practices across gender

\begin{tabular}{lllll}
\hline \multicolumn{1}{c}{ Variables } & & \multicolumn{3}{c}{ Gender } \\
\hline knowledge and practice questions & Options & Male & Female & P-value \\
\hline Duration of denture use & $<1$ years & $32(21.3)$ & $\mathbf{1 8 ( 1 2 )}$ & $\mathbf{0 . 0 0 3}$ \\
& $1-5$ years & $28(18.6)$ & $23(15.3)$ & Significant difference \\
& $>5$ years & $42(28)$ & $\mathbf{0 7}(4.6)$ & \\
Sleeping with prosthesis & Yes & $35(23.3)$ & $9(6)$ & 0.051 \\
& No & $67(44.6)$ & $39(26)$ & Significant difference \\
Storage of denture & Plastic bag & $03(2)$ & $0(0)$ & 0.327 \\
& Pocket & $02(1.3)$ & $0(0)$ & Not significant \\
& Under pillow & $02(1.3)$ & $0(0)$ & \\
Denture cleansing in a day & Plain Water & $95(63.3)$ & $48(32)$ & \\
& once & $35(23.3)$ & $31(20.6)$ & 0.002 \\
& Twice & $31(20.6)$ & $11(7.3)$ & Significant difference \\
& Thrice & $27(18)$ & $06(4)$ & \\
& More than- & $09(6)$ & $0(0)$ & \\
& Three times & & & \\
Method of instruction & only Verbal & $6(37.3)$ & $30(20)$ & 0.380 \\
& No Verbal or & $46(30.6)$ & $11(7.3)$ & Not significant \\
& Practical- & & & \\
& Demonstration & & \\
\hline
\end{tabular}

(Fig.3). Methods of cleaning were water (100\%), toothbrush $(71.3 \%)$, soap $(36 \%)$, toothpaste alongwith water $(23.3 \%)$. Only 1 patient $(0.7 \%)$ reported of using disinfecting denture cleanser solution. Only 15 (10\%) of the study subjects said they used a denture adhesive to aid in prosthesis retention. 145 subjects $(96.7 \%)$ believe that they can clean their prosthesis properly. It was observed that 63 individuals $(42 \%)$ individuals believe that denture can last from 5-10 years.

When asked about instructions given by the dentist or dental staff, 86 patients $(57.3 \%)$ told that they were given only verbal instructions about methods of cleaning while $64(42.7 \%)$ were not given any verbal instructions or practical demonstrations about any method of cleaning of denture.

\section{DISCUSSION}

The questionnaire for this study contained queries about several factors that can be attributed to the etiology of denture stomatitis i.e. duration of denture use, denture hygiene practices and lack of instructions by the dental professional for oral and denture hygiene maintenance. The study sample of 150 subjects was almost equally distributed among three groups regarding duration of denture use which is in agreement with the study done by Shankar et $\mathrm{al}^{2}$ and Peracini et al. ${ }^{8}$ However, studies done by Barbosa et $\mathrm{al}^{6}$ and Coelho et al ${ }^{13}$ reported $75 \%$ of the participants with denture usage of more than five years.

The present study reports that $29.3 \%$ subjects were sleeping with their denture in mouth overnight. In contrast, Shankar et $\mathrm{al}^{2}$ reported $13.2 \%$ subjects sleeping with prosthesis overnight. Some other studies had shown more complete denture wearers sleeping with prosthesis overnight with percentages ranging between $64 \%^{6}, 58.9 \%{ }^{12}$ and $55.2 \%{ }^{14}$ respectively. Frequency of denture stomatitis was more in subjects who were wearing their dentures while sleeping at night. ${ }^{15}$

When prosthesis was not in use e.g. at night, the major method of storage was plain water $(95.3 \%)$, which is significantly different from the study by Shankar et al ${ }^{2} 70 \%$. While other methods employed for storage of prosthesis were placing dentures in pocket, plastic bag or under pillow. This finding is in line with post-operative instructions given by the dentist.

In this study population, it was a surprising finding that $100 \%$ subjects were cleaning their prosthesis at least once a day. This result is similar to a study by Barbosa et $\mathrm{al}^{6}$ (98\%) and Marchini et al ${ }^{16}(98.7 \%)$. There is strong correlation between unsatisfactory cleaning of prosthesis and candida infection. ${ }^{6}$

When asked about method of cleaning, commonly used 
method was plain tap water by $100 \%$ subjects, while $71.3 \%$ subjects also used toothbrush along with water which is the results of Barbosa et al ${ }^{6}$ and Peracini et al. ${ }^{17}$ Other methods were toothbrush along with toothpaste and soap.

While answering the query about the use of disinfecting materials, only one individual of the study sample was found to be using commercially available disinfecting denture cleansing solution in contrast to other studies which reported $16.8 \%{ }^{6}$ and $11.4 \%^{2}$ of the sample size. Chemical cleansing agents are mainly cleaning tablets and sodium hypochlorite solution. According to Peltola et $\mathrm{al}^{18}$, the use of denture immersion disinfecting solution was infrequent (27.1\%) and most common immersion solution used was sodium hypochlorite $(54.7 \%)$.

Denture adhesive use was the major assistance required by the patients for adaptation to new dentures..$^{15}$ subjects $(10 \%)$ of the study sample were using denture adhesives. In another study, this percentage was only $1.3 \%{ }^{6}$ and a study without a single user of adhesive. ${ }^{19}$

When asked about satisfaction with the method of cleaning, astonishingly $96.7 \%$ individuals were satisfied. But, Hoadreddick et $\mathrm{al}^{12}$ had revealed in a study that $34.6 \%$ of individuals were not satisfied with their methods of cleaning.

When enquired about the perception of age of complete denture, $81.3 \%$ of the subjects believed that complete denture can last 5-10 years while $14.7 \%$ believe denture can last longer than 10 years. While study by Barbosa et $\mathrm{al}^{6}$ showed $44 \%$ denture wearers believe denture can last more than 10 years.

Enquiry about provision of denture hygiene instructions revealed that $57.3 \%$ subjects were only told about methods of denture cleaning by the dentist or any of the dental staff. The study by Hoadreddick et $\mathrm{al}^{12}$ has shown much better percentage than this i.e. $86.3 \%$ which were given verbal instructions about cleansing of denture and oral cavity. Old denture wearers are more susceptible to oral mucosal lesions, such as, denture stomatitis, angular cheilitis, candida infections and burning mouth syndrome. Denture care instructions should include the complete care about dentures and oral hard and soft tissues along with practical demonstrations by the dentist or dental staff. ${ }^{2}$ Daily oral hygiene habits are of prime importance as preventive method for mucosal lesions. ${ }^{20}$

Dentists should not only fabricate prosthesis but also provide their patients with detailed practical and realistic guidelines for the maintenance of prosthesis and oral hard and soft tissues. Complete denture patients should be instructed about the removal of prosthesis at night as well as the need to visit their dentist periodically for prosthesis and oral cavity evaluation. ${ }^{2,21}$

\section{CONCLUSIONS}

It is concluded that within the limitations of this study, most of the denture wearers had little knowledge of denture cleaning and hygiene practices. This study had revealed that oral hygiene habits and practices may not always be correlated positively with age, gender, method of prosthesis care and number of years of usage of prosthesis. By maintaining excellent denture hygiene, complete denture wearers can get maximum benefit out of their prosthesis for a longer period of time.

\section{CONFLICT OF INTEREST}

None declared

\section{REFERENCES}

1. Guiglia R, Musciotto A, Compilato D, Procaccini M, Russo LL, Ciavarella D, Muzio LL, Cannone V, Pepe I, D'Angelo M, Campisi G. Aging and oral health: effects in hard and soft tissues. Curr. Pharm. Des. 2010;16:619-30. https://doi.org/10.2174/138161210790883813

2. Shankar T, Gowd S, Suresan V, Mantri S, Saxena S, Mishra P, Panday P. Denture Hygiene Knowledge and Practices among Complete Denture Wearers attending a Postgraduate Dental Institute. J Contemp Dent Pract. 2017;18:714-21.

https://doi.org/10.5005/jp-journals-10024-2113

3. Tavares M, Calabi KA, San Martin L. Systemic diseases and oral health. Dent Clin N Am 2014;58:797-14.

https://doi.org/10.1016/j.cden.2014.07.005

4. de Arruda CN, Salles MM, Badaró MM, de Cássia Oliveira V, Macedo AP, Silva-Lovato CH, Paranhos HD. Effect of sodium hypochlorite and Ricinus communis solutions on control of denture biofilm: A randomized crossover clinical trial. J Prosthet Dent. 2017;117:729-34

https://doi.org/10.1016/j.prosdent.2016.08.035

5. Suresan V, Mantri S, Deogade S, Sumathi K, Panday P, Galav A, Mishra K. Denture hygiene knowledge, attitudes, and practices toward patient education in denture care among dental practitioners of Jabalpur city, Madhya Pradesh, India. J Indian Prosthodont Soc. 2016;16:305 .

https://doi.org/10.4103/0972-4052.175714

6. De Castellucci Barbosa L, Ferreira MR, de Carvalho Calabrich CF, Viana AC, De Lemos MC, Lauria RA. Edentulous patients' knowledge of dental hygiene and care of prostheses. Gerodontology.2008;25:99106.

https://doi.org/10.1111/j.1741-2358.2007.00190.x

7. Felton D, Cooper L, Duqum I, Minsley G, Guckes A, Haug S, Meredith P, Solie C, Avery D, Chandler ND. Evidence-based guidelines 
for the care and maintenance of complete dentures: a publication of the American College of Prosthodontists. J Am Dent Assoc.2011; 142(2 suppl):1S-20S

https://doi.org/10.14219/jada.archive.2011.0067

8. Peracini A, Davi LR, de Queiroz Ribeiro N, de Souza RF, da Silva $\mathrm{CH}$, Paranhos HD. Effect of denture cleansers on physical properties of heat-polymerized acrylic resin. J Prosthodont Res. 2010;54:78-83. https://doi.org/10.1016/j.jpor.2009.11.004

9. Pires CW, Fraga S, Beck AC, Braun KO, Peres PE. Chemical Methods for Cleaning Conventional Dentures: What is the Best Antimicrobial Option? An In Vitro Study. Oral Health Prev Dent. 2017;15:73-7.

10. Paranhos HF, Silva-Lovato CH, Souza RF, Cruz PC, Freitas KM, Peracini A. Effects of mechanical and chemical methods on denture biofilm accumulation. J Oral Rehabil. 2007;34:606-12.

https://doi.org/10.1111/j.1365-2842.2007.01753.x

11. Hoad-Reddick G, Grant AA, Griffiths CS. Investigation into the cleanliness of dentures in an elderly population. J Prosthet Dent. $1990 ; 64: 48-52$.

https://doi.org/10.1016/0022-3913(90)90152-3

12. Coelho CM, Sousa YT, Dare AM. Denture-related oral mucosal lesions in a Brazilian school of dentistry. J Oral Rehabil. 2004;31:1359.

https://doi.org/10.1111/j.1365-2842.2004.01115.x

13. Baran I, Nalçaci R. Self-reported denture hygiene habits and ora tissue conditions of complete denture wearers. Arch Gerontol Geriatr. 2009;49:237-41.

https://doi.org/10.1016/j.archger.2008.08.010

14. Raab FJ, Taylor CA, Bucher JA, Mann BL. Scanning electron microscopic examination of ultrasonic and effervescent methods of surface contaminant removal from complete dentures. J Prosthet Dent. 1991;65:255-58. https://doi.org/10.1016/0022-3913(91)90171-R

15. Marchini L, Tamashiro E, Nascimento DF, Cunha VP. Selfreported denture hygiene of a sample of edentulous attendees at a University dental clinic and the relationship to the condition of the oral tissues. Gerodontology. 2004;21:226-28. https://doi.org/10.1111/j.1741-2358.2004.00026.x

16. Peracini A, Andrade IM, Paranhos HD, Silva CH, Souza RF. Behaviors and hygiene habits of complete denture wearers. Braz Dent J. 2010;21:247-52 https://doi.org/10.1590/S0103-64402010000300013

17. Peltola MK, Raustia AM, Salonen MA. Effect of complete denture renewal on oral health-a survey of 42 patients. J Oral Rehabil. 1997;24:419-25.

https://doi.org/10.1046/j.1365-2842.1997.00510.x

18. Özcan M, Kulak Y, Arikan A, Silahtar E. The attitude of complete denture wearers towards denture adhesives in Istanbul. J Oral Rehabil. 2004;31:131-34. https://doi.org/10.1046/j.0305-182X.2003.01224.x

19. Nevalainen MJ, Närhi TO, Ainamo A. Oral mucosal lesions and oral hygiene habits in the home?living elderly. J Oral Rehabil. 1997;24:332-37.

https://doi.org/10.1046/j.1365-2842.1997.d01-298.x

20. Budtz-Jørgensen E. Materials and methods for cleaning dentures. J Prosthet Dent. 1979;42:619-23. https://doi.org/10.1016/0022-3913(79)90190-2 